\title{
Familial partial trisomy of the long arm of chromosome 3 (3q)
}

\section{CLAUDINE FEAR AND ALLEN BRIGGS}

\author{
Paediatric Research Unit, Prince Philip Research Laboratories, and Department of Paediatrics, Guy's Hospital, \\ London
}

SUMmaRY A case of partial trisomy of the long arm of chromosome 3 (3q21 $\rightarrow$ qter) is described. The clinical findings are compared with those in 5 previously reported cases. There is hirsutism and characteristic facial dysmorphism, the common features of which are a square-shaped face, prominent nasal bridge, everted nostrils, hypertelorism, and palate abnormalities; occurring less often are abnormalities of vertebrae, thorax, and digits, or cardiovascular, urinogenital, and central nervous system. New features noted in this present case are absence of right eye from orbit and spina bifida. The spectrum of this syndrome is discussed, with possible relation to the degree of trisomy. The present case is the 6 th to be reported with partial trisomy of the long arm of chromosome 3 .

\section{Case report}

The propositus (Fig. 1) was the result of a 3rd pregnancy of the mother; she had had 2 phenotypically normal children from a previous marriage. The pregnancy was noted for small fetal size, lack of intrauterine movements, and recurrent small antipartum haemorrhages. Urinary oestriol excretion was low throughout the pregnancy. The child was delivered by emergency caesarean section when the mother presented in labour with a fetal heart rate of 80 .

The child, a girl, with multiple congenital anomalies, died soon after delivery. Clinical features included: a square-shaped face; wide nasal bridge and everted nostrils; small malformed and malpositioned ears; absence of right eye; high arched palate; a short webbed neck; clinodactyly of the 5th fingers; lumbar meningomyelocele with congenital dislocation of both hips, and bilateral talipes equinovarus. $X$-ray of the chest showed hypoplasia of the right first rib.

Necropsy (Guy's Hospital, no. 362/76) (Dr J. Heaton) showed absence of the roof of the right orbit and the dysplastic right eye was found in the anterior cranial fossa. Large anterior and posterior sagittal fontanelles separated the bones of the vault of the skull. The brain $(250 \mathrm{~g})$ was sectioned to show

Paediatric Research Unit, Prince Philip Research Laboratories, and Department of Paediatrics, Guy's Hospital, London CLAUDINE FEAR, research assistant

ALLEN BRIGGS, senior registrar

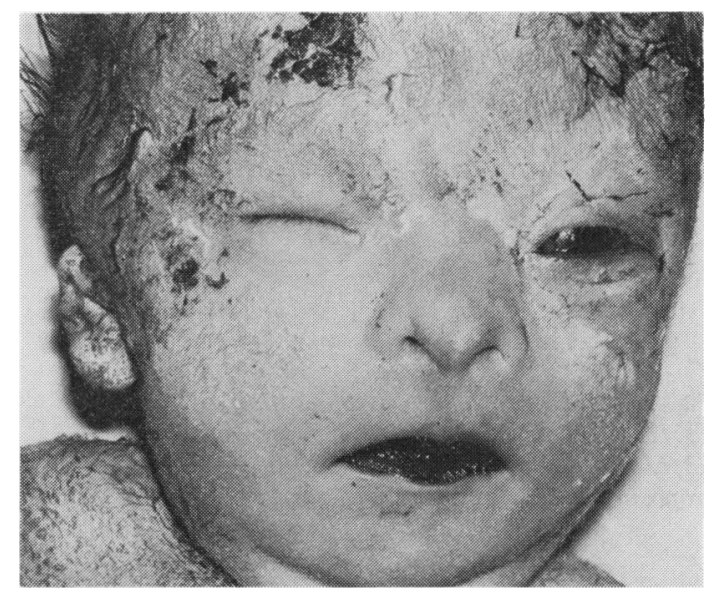

Fig. 1 The propositus, note square-shaped face, malformed ears, absence of right eye.

diffuse dilatation of the ventricular system consistent with internal hydrocephalus. There was a large atrial septal defect. The left kidney and part of the right kidney showed pin-point sized cysts which were visible both externally and on the cut surfaces. There were also bilateral double ureters draining the cystic dysplastic kidneys; on the left side both were severely dilated and kinked; on the right only one was dilated.

Chromosome studies. Chromosomes prepared from cultured skin fibroblasts and lymphocytes from the 
propositus were either banded with trypsin and stained with Geimsa ( $G$ bands) or stained with quinacrine mustard to give $\mathbf{Q}$ bands. Analysis showed additional chromosomal material on the

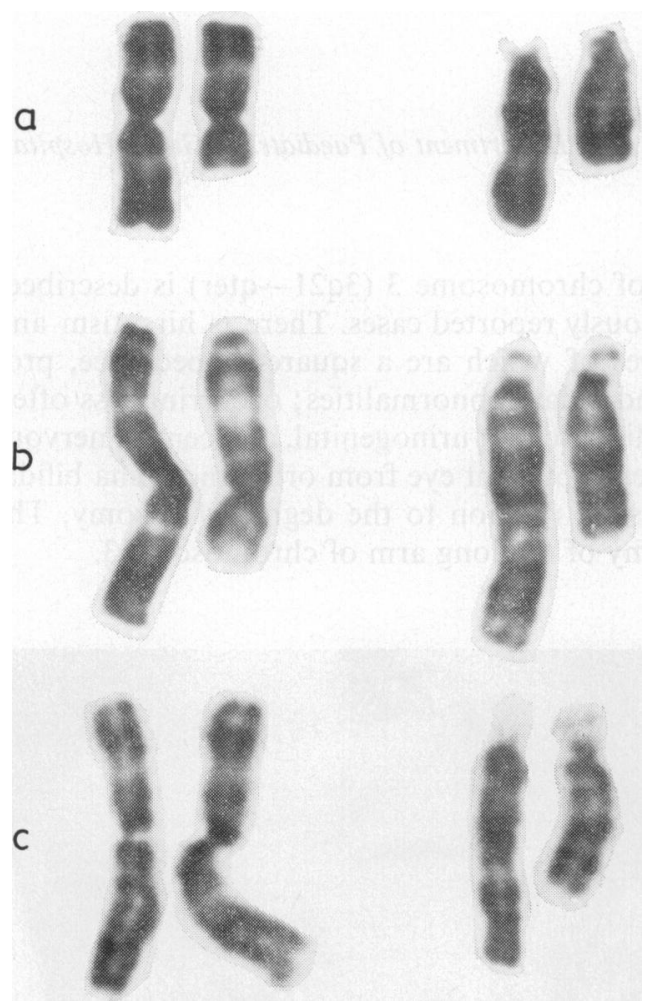

Fig. 2 (a) balanced chromosomes mother $t(3 ; 13)(q 21 ; q 34) ;(b)$ balanced chromosomes daughter $t(3 ; 13)(q 21 ; q 34) ;(c)$ unbalanced chromosomes propositus der(13)t( $3 ; 13)(q 21 ; q 34)$ mat. long arms of no. 13 (Fig. 2c). Subsequent studies of the mother's chromosomes showed a balanced translocation between the long arms of nos 3 and 13 (Fig. 2a), which may be expressed as: $46, X X, t(3 ; 13)$ (q21;q34), and the child's unbalanced chromosome constitution as: $46, \mathrm{XX}, \operatorname{der}(13), \mathrm{t}(3 ; 13)(\mathrm{q} 21 ; \mathrm{q} 34)$ mat. The propositus therefore had 2 normal chromosomes no. 3 and an abnormal no. 13 to which a large additional segment of the long arm of no. 3 was attached, with slight loss of the terminal region of 13q.

One of two sisters carried the translocation in the balanced form (Fig. 2b) and the other sister had a normal female chromosome complement.

The maternal great-grandparents (Fig. 3) (I,3 and I,4) had 17 children, 10 of whom died neonatally. The maternal grandmother (II,9) had 3 miscarriages out of 7 pregnancies, while the maternal aunt (III,4) had 3 miscarriages and one neonatal death from 4 pregnancies and was then sterilised. The index family has two phenotypically normal children and the propositus.

In three generations about half the number of babies known to have been conceived had survived pregnancy. The losses were attributable to miscarriage and neonatal death and it is probable that most were the result of the translocation in an unbalanced form. However, there are no details of these except that at least 6 were miscarriages.

\section{Discussion}

Table 1 lists the features of 5 known cases of partial trisomy 3q and a 6th case (Clarke et al., 1964) in which there was no banding information but as the clinical features were similar it is felt that there is justification for its inclusion. All have in common the square-shaped face with prominent nasal bridge

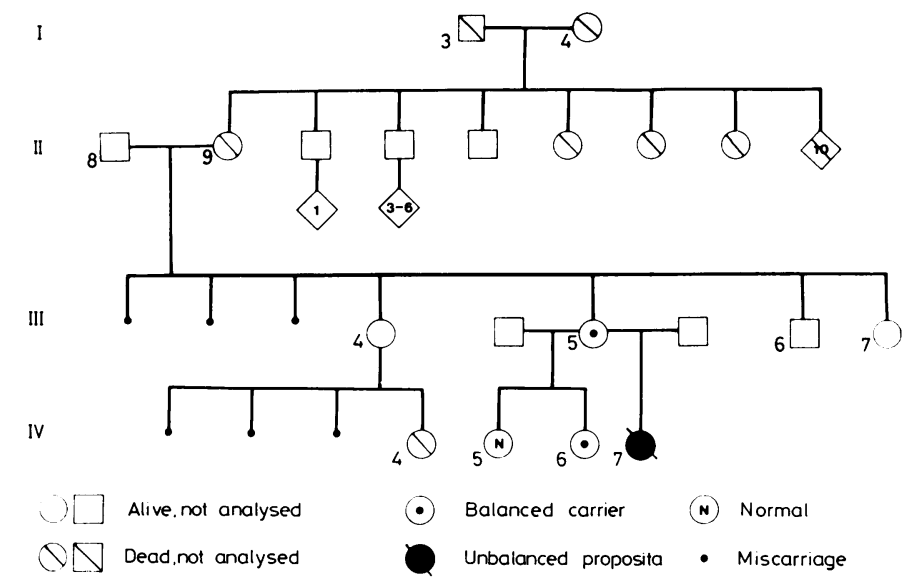

Fig. 3 Family tree. 
Table 1 Findings in 6 cases of partial trisomy of long arm of chromosome 3

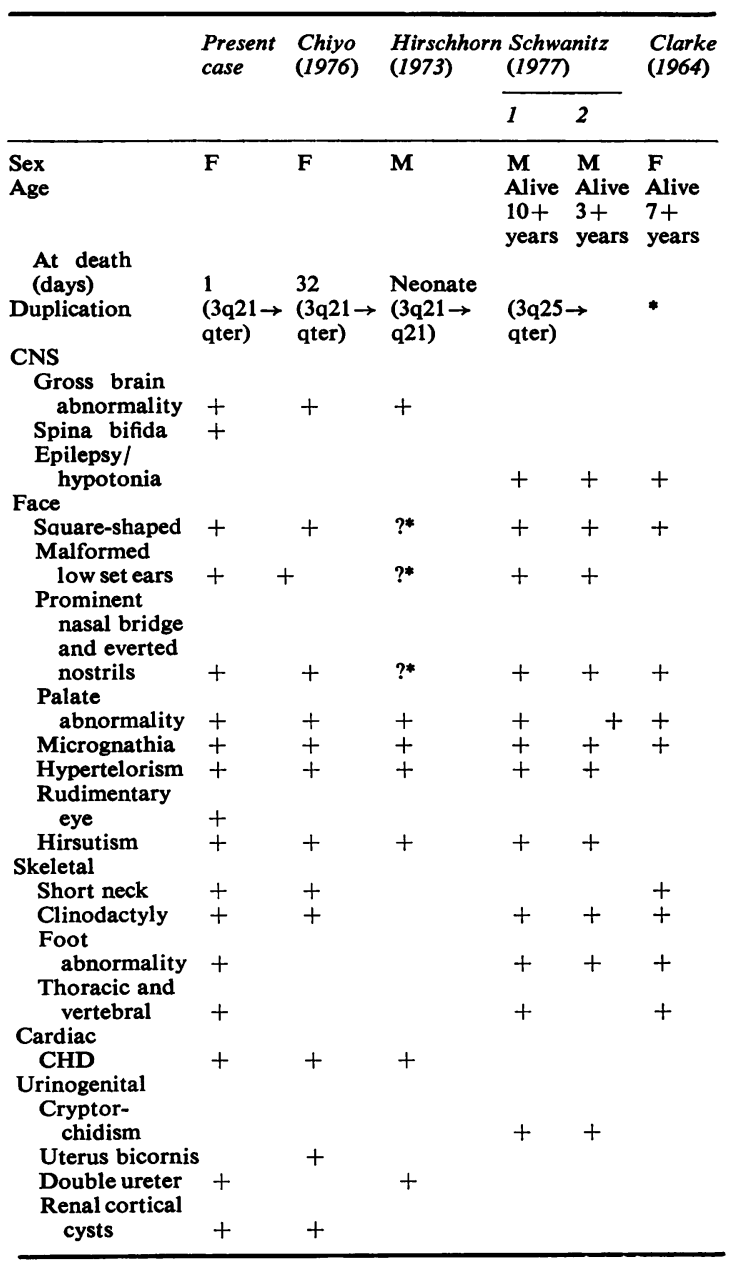

*Not described.

everted nostrils, hirsutism, hypertelorism, and palate abnormalities. Other features present in decreasing frequency are micrognathia, malformed low-set ears, clinodactyly, foot abnormalities, webbed neck, thoracic and vertebral defects, and urinogenital abnormalities. Features noted in isolation include deafness, cataracts, abnormal thumb insertion, syndactyly, short 5th metacarpal (Schwanitz et al., 1977). Clarke et al. (1964) and Schwanitz et al. (1977) also noted hyperextensible joints and bilateral single palmar creases. Features in the present case not previously described are microphthalmia and meningomyelocele.

In these 6 cases of partial trisomy $3 q, 3$ died
Table 2 Chromosome abnormalities in 5 infants with partial trisomy of long arm of chromosome 3, and in their parents

\begin{tabular}{|c|c|c|}
\hline $\begin{array}{l}\text { Present case } \\
\text { Balanced } \\
\text { Unbalanced }\end{array}$ & $\begin{array}{l}\text { Mother } \\
\text { Neonatal death }\end{array}$ & $\begin{array}{l}46, X X, t(3 ; 13)(q 21 ; q 34) \\
46, X X, \operatorname{der}(13), t(3 ; 13)(q 21 ; q 34) \\
\text { mat }\end{array}$ \\
\hline \multicolumn{3}{|c|}{ Chiyo et al. (1976) } \\
\hline $\begin{array}{l}\text { Balanced } \\
\text { Unbalanced }\end{array}$ & $\begin{array}{l}\text { Mother } \\
\text { Neonatal death }\end{array}$ & $\begin{array}{l}46, X X, t(2 ; 3)(p 25 ; q 21) \\
46, X X, \operatorname{der}(2), t(2 ; 3)(p 25 ; q 21) \text { mat }\end{array}$ \\
\hline \multicolumn{3}{|c|}{ Hirschhorn et al. (1973) } \\
\hline $\begin{array}{l}\text { Balanced } \\
\text { Unbalanced } \\
\text { (meiotic recor }\end{array}$ & $\begin{array}{l}\text { Father } \\
\text { Stillbirth } \\
\text { mbination) }\end{array}$ & $\begin{array}{l}\text { 46,XY,inv(3) (p25;q21) } \\
46, X Y, \text { rec(3),dup q,inv(3) } \\
(\mathrm{p} 25 ; \mathrm{q} 21)\end{array}$ \\
\hline \multicolumn{3}{|c|}{ Schwanitz et al. (1977) } \\
\hline $\begin{array}{l}\text { Balanced } \\
\text { Unbalanced }\end{array}$ & $\begin{array}{l}\text { Mother } \\
\text { Cases } 1 \text { and } 2 \\
\text { alive }\end{array}$ & $\begin{array}{l}46, \mathrm{XX}, \mathrm{t}(3 ; 22)(\mathrm{q} 25 ; \mathrm{p} 11) \mathrm{mat} \\
46, \mathrm{XY}, \mathrm{der}(22), \mathrm{t}(3 ; 22) \\
(\mathrm{q} 25 ; \mathrm{p} 11) \mathrm{mat}\end{array}$ \\
\hline \multicolumn{3}{|c|}{ Clarke et al. (1964) } \\
\hline $\begin{array}{l}\text { Balanced } \\
\text { Unbalanced }\end{array}$ & $\begin{array}{l}\text { Mother } \\
\text { Daughter alive }\end{array}$ & $\begin{array}{l}46, X X, t(3 / C) \\
46, X X,-C,+C q+ \\
\text { (no banding data available) }\end{array}$ \\
\hline
\end{tabular}

neonatally (present case; Hirschhorn et al., 1973; Chiyo et al., 1976) and 3 survived into childhood (Clarke et al., 1964; Schwanitz et al., 1977). The survivors did not have the gross abnormalities of heart and brain which were incompatible with life but they all had hypotonia, epilepsy, and moderate mental retardation.

The reported cases, and our own, had unbalanced chromosome abnormalities which resulted from structural anomalies in a carrier parent (5 maternal, 1 paternal) (Table 2). An inversion was present in one (Hirschhorn et al., 1973) and the remaining 5 were the result of reciprocal translocations involving $3 q$ with other chromosomes. Nevertheless, we note that 3 cases have similar break points (3q21) (Hirschhorn et al., 1973; Chiyo et al., 1976; present case). It may be significant that they have a similar clinical pattern. Two of the milder cases, brothers, had a more distal break point (3q25) and are therefore trisomic for a smaller portion of 3q (Schwanitz et al., 1977). In the 6th case (Clarke et al., 1964) the actual break points were not established.

The only important factor is the duplication of 3q; the deficiencies of the other chromosomes are slight, since only their terminal bands are involved, present case (13q34), Chiyo (2p25), and Schwanitz (the heterochromatic regions of $22 p$, which are generally thought to be genetically inert). In Hirschhorn's case the 3 alone is involved and the details of the break points in Clarke's case are not known.

From such a small group of cases the range of abnormalities associated with partial trisomy 3q cannot be defined. The features common to these cases provide a characteristic facial appearance by which others may be suspected, but a chromosomal diagnosis should always be established. 
We thank Dr Leo Stimmler, Department of Paediatrics, Guy's Hospital, for referral of the propositus, and Dorothy Garrett for technical assistance.

This work was partly supported by the Spastics Society and the Department of Health and Social Security.

\section{References}

Chiyo, H., Kuroki, Y., Matsui, I., Niitsu, N., and Nakagome, Y. (1976). A case of partial trisomy 3q. Journal of Medical Genetics, 13, 525-528.

Clarke, G., Stevenson, A. C., Davies, P., and Williams, C. E. (1964). A family apparently showing transmission of a translocation between chromosome 3 and one of the 'X-6-12' or 'C group'. Journal of Medical Genetics, 1, 27-34.

Hirschhorn, K., Lucas, M., and Wallace, I. (1973). Precise identification of various chromosomal abnormalities. Annals of Human Genetics, 36, 375-379.

Schwanitz, G., Schmid, R. D., Grosse, G., and Grahn-Liebe, E. (1977). Translocation familiale $3 / 22$ mat. avec trisomie partielle 3q. Journal de génétique humaine, 25, 141-150.

Correspondence to Dr Claudine Fear, Paediatric Research Unit, Prince Philip Research Laboratories, Guy's Tower, St Thomas Street, London SE1 9RT.

Received 22 May 1978 